\title{
Cultural Care of Pregnancy and Home Birth: An Application of the Sunrise Model
}

\author{
Elena Andina-Díaz, PhD \\ Faculty of Health Science, Nursing and Physiotherapy Department, University of \\ León, León, Spai \\ Nursing and Culture of Care, University of Alicante, Spain \\ Health Research Group, Welfare and Social and Health Sustainability, University of \\ León, Spain \\ José Siles-González, $\mathrm{PhD}$ \\ Nursing and Culture of Care, University of Alicante, Spain \\ Faculty of Health Science, Nursing Department, University of Alicante, Alicante, \\ Spain
}

Background and Purpose: The role of older women close to the pregnant woman may be relevant when conveying information. The use of theories/models can guide the development of nursing practice. Purpose: To explore beliefs and practices related to pregnancy and childbirth from the perspective of older women who gave birth at home, applying Leininger's Sunrise Model. Methods: Qualitative approach, using semi-structured interviews with 24 older women who gave birth at home (rural area, Spain). Manual content analysis of the data was used, and Sunrise Model guided to explore the role of culture and the factors affecting maternity care. Results: Two main categories emerged: beliefs/practices related to physiological aspects (subcategories: minimal intervention, hygiene, pain control, rest, feeding) and to psychosocial aspects (subcategories: spiritual well-being, company). Implications for Practice: The experiences of older women who gave birth at home helped us to understand some beliefs that survive in some pregnant women, similar in different cultures, and divided into physiological and psychosocial aspects. An interesting fact to consider to provide cultural care. Older women have a relevant role as transmitters of information, and can provide some keys to plan health interventions, as companions or counselors. Applying the Sunrise Model, we verified the weight that culture has in maternal health care, and the multiple factors that interfere with the way of caring. The application of models helps us to improve nursing practice: not only should we focus on knowing the physical aspects, but also the social and cultural circumstances surrounding the pregnant woman. 
Keywords: transcultural nursing; maternal-child nursing; qualitative research

$\mathrm{N}$ ot only is the birth of a new human being a biological fact, but also a social one, a rite of passage which has been accompanied by a multitude of beliefs and practices pervaded by cultural aspects. This birth has been represented according to the ideologies that have dominated every social context (Hernández \& Echevarría, 2015). Changes and advances in medicine in recent centuries have transformed the way of managing motherhood, displacing, sometimes, popular beliefs and ancestral practices by others based on scientific knowledge (Lledó et al., 2017).

Different studies show that those beliefs and practices transmitted from generation to generation, generally through women (relatives and traditional birth assistant [TBA]), coexist with scientific practices (e.g., in isolated communities in India or China) (Gyaltsen et al., 2014; Kyei-Nimakoh et al., 2017; Laza, 2015; Pati et al., 2014). Popular beliefs and practices survive in many communities around the world (Bradley et al., 2016; Owens et al., 2016).

This fact is interesting from the health point of view, since some of these beliefs and practices may become obstacles, and may negatively influence health. The World Health Organization (WHO) estimates that 830 women die every day owing to complications related to pregnancy or childbirth. In addition, one of the obstacles preventing women from receiving the necessary care during childbirth is cultural practices. With the aim of reducing the number of maternal deaths, one of the goals within the Sustainable Development Goal 3 is to strengthen the health systems, collecting quality data that respond to the needs of women (WHO, n.d.).

Different studies evidence that the provision of professional care adapted to cultural needs generates a positive impact on women, their babies and their family (Benza \& Liamputtong, 2014; Withers et al., 2018). Current recommendations suggest the offer to women of effective social, cultural, emotional, and psychological support, in a respectful manner (Coast et al., 2016; Tuncalp et al., 2015; WHO, 2016).

Bearing in mind this cultural connection, the role played by the older women close to the pregnant woman (mothers, grandmothers) may be relevant when conveying information and making health decisions (Dörnemann \& Kelly, 2013; Mukunya et al., 2018; Mukunya et al., 2019). Therefore, several studies evidence how getting to know their perspective can help us plan participatory health actions (involving the women/family/community), to provide care adapted to the culture, and to correct harmful practices (Joseph \& Earland, 2019; Kandasamy et al., 2017; Scelza \& Hinde, 2019).

In this research, we would like to explore the beliefs and practices of older women who gave birth at home in a rural area of the geography of Spain. The fact of knowing their experiences can help us to understand the origin and weight of some beliefs conveyed from generation to generation, and which survive nowadays in some pregnant women, and that we should consider in order to provide cultural 
care these days. On the other hand, it can provide us some keys to plan maternal health interventions in which these older women become involved, because they gave birth at home, and due to the interest that may arise in relation to childbirth at home, that it has recently increased in many countries (Fdez, 2014).

For this purpose, we applied a nursing model. The use of theories and models can help the reflection of basic aspects of our profession, the simplified representation of reality, and the development in our practice (Wehbe-Alamah, 2015). The chosen one was the Sunrise Model, by Leininger. She was the first nurse who defined health care considering cultural aspects, establishing among its principles, the existence of differences and common aspects in health care depending on the culture and on structural factors (such as religion, economy, or social factors) which influence the way of caring (Wehbe-Alamah, 2015). Her theory has been used in numerous studies in recent decades (Abdulrehman et al., 2016; Fernandes et al., 2018; Tavares et al., 2016). Its use can help us explore the role of culture in terms of beliefs and practices related to pregnancy and childbirth, and determine the factors affecting it (economy, education, health policy, cultural values, or religion).

The purpose of this research is: To explore beliefs and practices related to pregnancy and childbirth from the perspective of older women who gave birth at home, applying Leininger's Sunrise Model.

\section{METHOD}

As the aim of the study was to explore beliefs and practices related to pregnancy and childbirth from the perspective of older women who gave birth at home, the researchers designed a qualitative approach. This approach holistically allowed to explore the cultural awareness of maternal care, providing the insider's perspective of participants and not the biomedical perspective. The method used to collect the information was the semi-structured interview.

The study was carried out from April to September 2012, in the rural municipalities of Almanza and Cebanico (León, Spain), with a total of 16 villages.

Participants were women who gave birth at home. The inclusion criteria were: women born in this area, over 60 years old, whose pregnancy and childbirth took place at home in this area, and cognitively able to share their experiences. The exclusion criteria were: lack of desire to participate in the study.

After obtaining the ethical permits (UA-2015-08-18), a convenience sampling was performed. The principal investigator (PI) was a neighbor and well-known person in the area. She contacted women who met the inclusion criteria, in each village, and invited them to participate in the study. The PI used the fact of knowing the sources to establish the relationship and select the most appropriate participants. Using the snowball technique, and being advised by participants and neighbors, the PI contacted other possible participants. Finally, 24 women were 
contacted (at least, there was one participant in each town). All agreed to be interviewed. All of them were housewives who had between 1 and 17 deliveries at home, and they were between 68 and 92 years old.

The technique used to collect the data was the semi-structured interview. Researchers worked with an updated guide from a previous pilot trial as question guide (author, date). The information obtained is part of a far-reaching investigation (XXX), and within this document, we use information related to cultural issues. Interviews were conducted in the homes of participants. Written consents were obtained from all participating women and ethical aspects were taken into consideration (Declaration of Helsinki). An audio recorder was used to collect the data. The average length of each interview was of 60 minutes. The PI, the person interviewed and, sometimes, a family member of the person interviewed were present during the course of the interview (this member also signed the informed consent). A second follow-up visit was made to the participants, to clarify the answers and explore emerging issues. Data saturation was reached with 24 women.

The interviews were transcribed by the PI, and listened and revised by the secondary investigator, in order to confirm the transcription. Manual content analysis of the data was used to generate common topics. The analysis was conducted by both the researchers, based on the transcribed data, (a) discovering, (b) coding, and (c) relativizing data (Taylor \& Bogdan, 1990). Data were coded and grouped into seven subcategories, and encompassed into two main categories: beliefs and practices related to physiological and to psychosocial aspects. These categories were discussed between the two researchers to identify and reach consensus on their relevance and order. Leininger's Sunrise Model was applied to explore the role of culture and the factors affecting maternity care (economics, education, health policy, cultural values, or religion). To this effect, when analyzing each of the emerged subcategories, we reflected on how the different factors identified by Leininger could have an impact on them. On the other hand, a graphic representation of the data was made, according to the model.

\section{RESULTS}

Those beliefs and practices related to pregnancy and childbirth were divided into seven subcategories: minimal intervention, hygiene, pain control, rest, feeding, spiritual well-being, company. Likewise, as above mentioned, these subcategories were clustered into physiological and psychosocial aspects (Table 1).

\section{Beliefs and Practices Related to Physiological Aspects}

Minimal Intervention. For the women interviewed, pregnancy and childbirth were natural events. During pregnancy, "We never went to the doctor" (I21). This fact could have been influenced by social and family factors in a rural community, where women's work was so important: "I did not have anyone to help me at home" (I22). However, in addition, the economic factors could have influenced, because in 


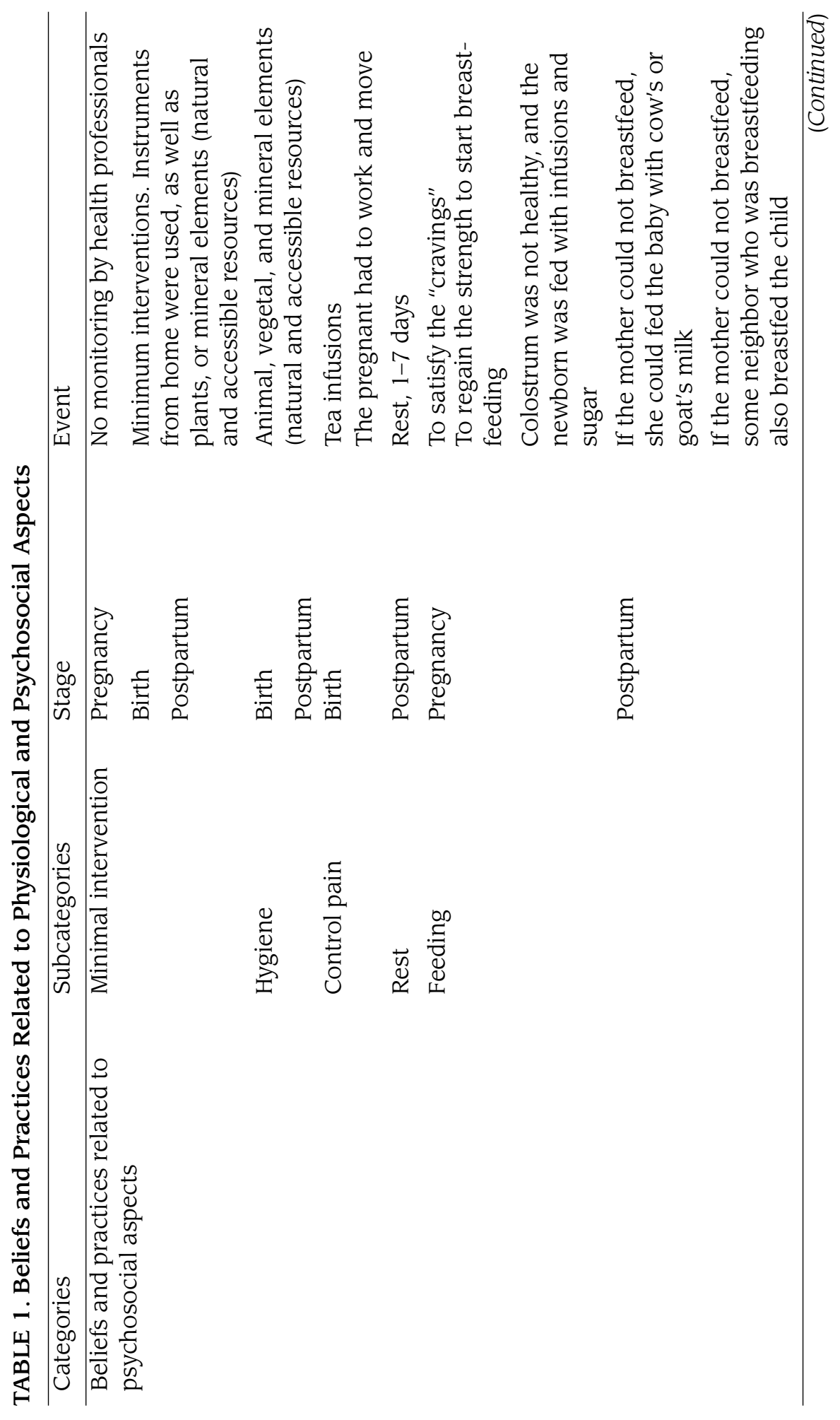




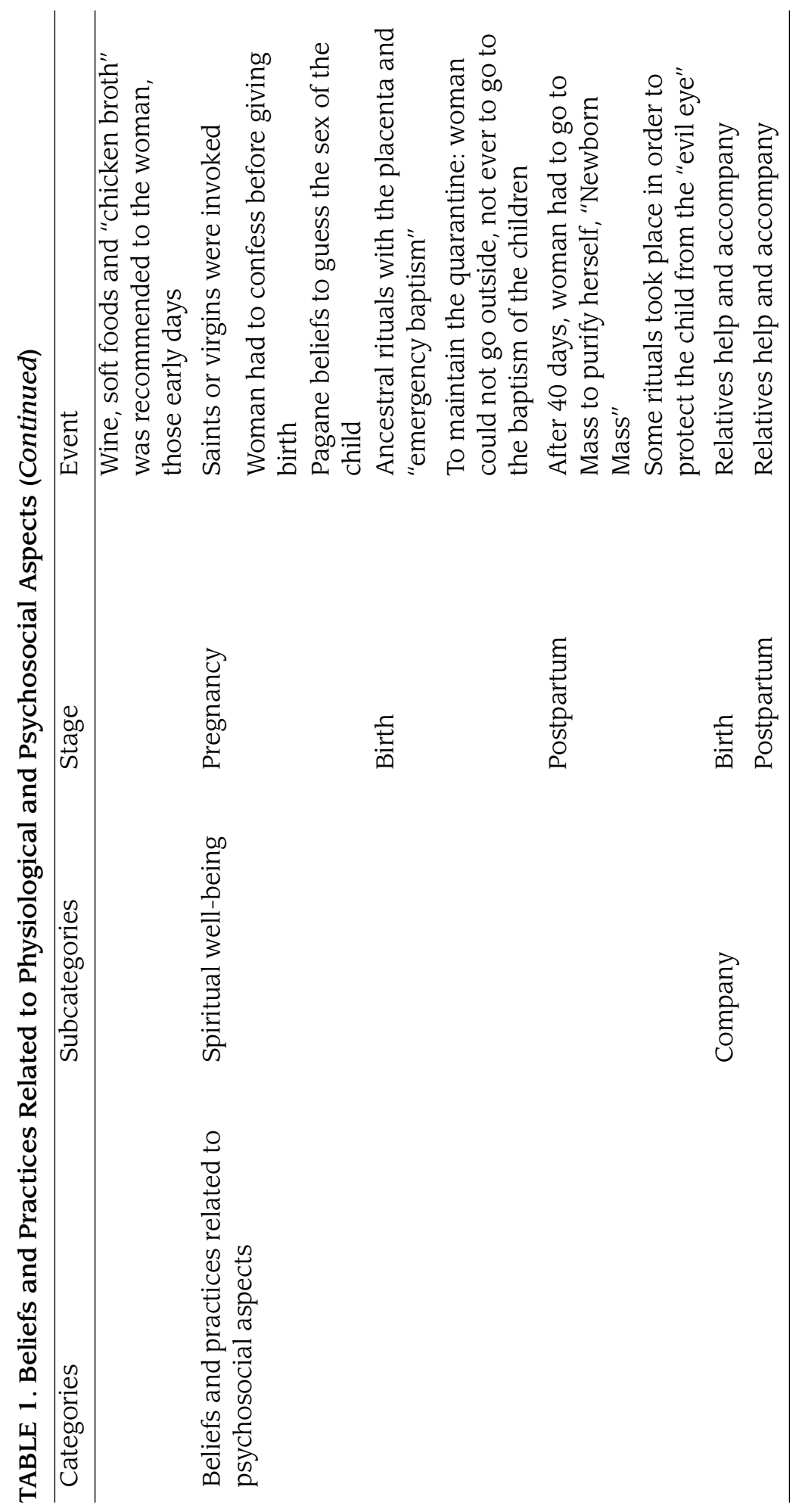


this area there were three doctors and three nurses for all the villages, and people had to pay to be assisted. Likewise, once the woman was in labour, "The TBA just came to take the newborn and clean him/her, because I already had everything ready" (I25). Family members or the TBA used everyday instruments from home, as well as plants or mineral elements (salt to recognize the position of the baby at birth), or animals (dogs, to stimulate the increase of milk for breastfeeding). Natural and accessible resources, and technological factors, conditioned thus the care.

Hygiene. Hygiene measures: "I always listened to her/him (TBA): 'You have to wash your hands"' (I25), "Clean your hands with soap and water" (I1); they all were in line with the recommendations of that time. They also used animal, vegetable, and mineral elements (natural and accessible resources). For example, fire ash or tallow to disinfect the navel of the newborn. Once again, natural resources, as well as educational factors conditioned the way of providing assistance.

Pain Control. For the pain of childbirth, they recommended tea infusions, lime blossom tea, or chocolate. In addition, cultural beliefs also persisted: "If you worked hard, the bones work well and you had few pains, so it is good to exercise and walk during pregnancy" (I20).

Rest. Family responsibilities (social and cultural factors) determined the rest patterns. Therefore, some women said "A few days in bed, so that the bones can go back to their place" (I7), and others "The child was born at 3 o'clock in the morning one day. The following day, at 9 in the morning, I left the cows to drink water. I didn't stop in bed, I had to work" (I18).

Feeding. If the woman had a craving for any food during pregnancy, she would satisfy it to prevent the child from being born, according to a belief (cultural values), with a mark on the body.

After birth, the woman had to regain her strength and take care of her body to start breastfeeding. A typical meal in those early days was "chicken broth": "They recommended (mother, sister, TBA) you to eat light meals, such as 'chicken broth"' (I6). Women usually prepared it "My mother gave me broth 2 or 3 days and also omelette" (I13). Other recommended foods were wine, and soft foods.

The newborn, during the first days, was fed with infusions of lime or chamomile with sugar, "My sister prepared chamomile, because the child cried and was hungry, with a little bit of sugar" (I10), because it was believed that colostrum was not healthy. Once the first few days had elapsed, if the mother could not breastfeed, she fed the baby with cow's or goat's milk (accessible resources), or they followed an ancient and supportive tradition (cultural and social factors), and some neighbor who was breastfeeding also breastfed that child: "The neighbour's wife fed my mother" (I25).

\section{Beliefs and Practices Related to Psychosocial Aspects}

Spiritual Well-Being. Christian religious beliefs and practices accompanied these moments (religious and philosophical factors). Thus, saints or virgins were invoked: "I prayed a lot to San Antonio for the pregnancy to go well, my mother 
insisted on the need to do it" (I1), and "All women had to confess before giving birth" (I9).

There were also pagan beliefs in order to guess the sex of the child, "They asked me which day I got pregnant, and they looked up what type of moon was it that day, and as it was a first quarter moon, they told me I would have a boy" (I3).

After birth, following certain ancestral rituals, the placenta was buried with animal waste. Some rituals took place in order to protect the child from the "evil eye."

And if the child died, an "emergency baptism" was carried out: holy water was administered to make him/her a Christian before burying him/her: "My mother baptised her. When the priest arrived and he was told what she had done (my mother), he said: 'well, the child is already baptised, because what this lady did is legal"' (I24).

Another tradition with high religious value was to "maintain the quarantine." During 40 days, women could not go outside, not even to go to the baptism of their children. A woman recalled proudly how she had been the first woman to attend her child's baptism, "I was the first woman in town to go to the baptism of my child" (I12). The tradition of maintaining the "quarantine" was lived between respect and fear, and was not always accepted, as it interfered with the development of their

AQ1 domestic routine: "You could not leave the house back then, because the priests would not let you out. I went down here so that they would not see me, to give green rye to the cows, and when I brought the packages behind me, a neighbor told me "I will tell the priest," and I said: "Tell him, and both of you come and help me" (I18). Once the 40 days elapsed, women could go outside. Beforehand, they had to go to Mass to purify themselves, the "Newborn Mass": "After a month, we went to church with the candle and the money to pay for the priest's mass; we were in sin" (E14).

Company. The family, TBA, and close friends played an important role during these moments. The neighboring people (community) rang the church bells so that the whole town knew there was a birth. The relatives killed a chicken, and with the meat, prepared the broth: "My aunt killed a chicken" (I13). The husband participated: "My husband stayed with me, because the TBA was small and she had no strength" (I23).

After the birth, the family and relatives celebrated it: "After the birth, they (relatives -women-) celebrated it, they made an omelette or chocolate" (I14). They also prepared the broth: "I was at my mother's house, and she prepared it along with my sister-in-law" (I7). The neighbors (women) visited the woman and brought her food: "the neighbours (women) gave me chocolate, half a dozen eggs; we called it 'the visit"' (I14).

Applying the Sunrise Model, we reflected on how beliefs and practices were conditioned by technological factors (accessible resources to provide medical care), religious factors (faith in God generated those practices), social factors (in a rural community, not only did women have an important role for the family economy, 


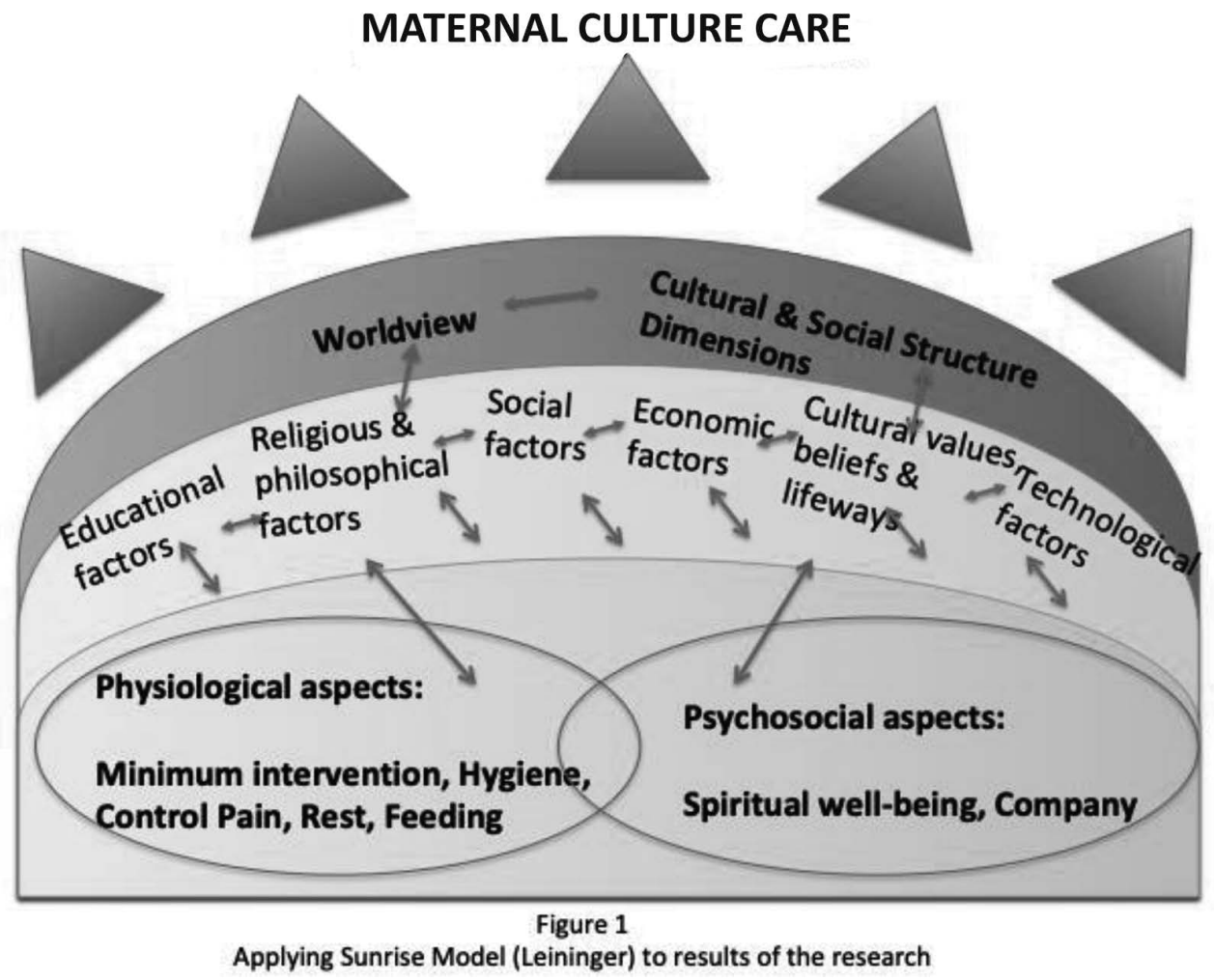

Figure 1. Applying Sunrise Model (Leininger) to results of the research.

but also the family and neighborhood), cultural factors (natural childbirth, biological role of women), economic factors (no access to health professionals), or educational factors (hygiene's norms). The structure of this rural community conditioned the way in which these women built an image of motherhood and, therefore, maternal care. For this reason, the culture of this community had a relevant impact on maternal care.

In Figure 1, we can see the results achieved, applying the Sunrise Model.

\section{DISCUSSION}

This study has explored some beliefs and practices related to pregnancy and childbirth, from the perspective of older women who gave birth at home in a rural area of Spain, thus fulfilling the objective. In addition, if we compare the results obtained with current literature, we establish many similarities. The two categories obtained from the results are consistent with the concerns of women during maternity collected in a recent qualitative systematic review, which describe birth as an incarnate experience of physiological and psychosocial nature (Downe et al., 2018). In 
this line, the WHO consider the need of maintaining the physical and sociocultural normality of the pregnant woman (WHO, 2016).

Among the emerged subcategories appears, as shown in the results, the need to experience pregnancy and childbirth as a natural process, fact which has been considered a recurrent issue in several systematic reviews (Benza \& Liamputtong, 2014; Withers et al., 2018). Another subcategory is the need to maintain minimum standards of hygiene and to use elements of the local economy, which was also mentioned in the work carried out in Brunei or Mexico (Abdul-Mumin, 2016; Dimmitt-Champion, 2013). In line with our results, in other studies conducted in other areas of the planet, tea, coffee, or seeds were used to control labour pain (Benza \& Liamputtong, 2014; Van Dijik et al., 2013; Withers et al., 2018). In other studies, the specific dietary recommendations for women after childbirth are similar (Benza \& Liamputtong, 2014), including vegetables, sugar and cinnamon tortillas with tea, in Mexico (Dimmitt-Champion, 2013), onions or potatoes in Turkey, melon in Iran, or honey, red tea, and cow's milk in India (Pati et al., 2014).

As for the needs of spiritual well-being, in other studies women also invoked saints or virgins (Abdul-Mumin, 2016; Dimmitt-Champion, 2013; Gyaltsen et al., 2014), performed rites after expelling the placenta (Abdul-Mumin, 2016; Laza, 2015), or administered concoctions to the newborn to protect him/her from the socalled "evil eye" (Sumankuuro et al., 2018). On the practice of "emergency baptism," in other cultures, such as the Mexican, there was a similar belief, by which the dead child born had to be buried under a stream of water, the water prevented him/her from staying in limbo (Dimmitt- Champion, 2013). The practice of "quarantine" is still present in some cultures of Asia and is practiced by some immigrant women (Benza \& Liamputtong, 2014). Finally, we find studies that emphasize the importance of companionship (Downe et al., 2018; Scelza \& Hinde, 2019; Sumankuuro et al., 2018; WHO, 2016).

In many of these studies cited above, as in ours, the role that older women, family, and relatives were significant, as transmitters of maternal health information. This is in line with other authors (Dörnemann \& Kelly, 2013; Joseph \& Earland, 2019; Kandasamy et al., 2017; Mukunya et al., 2018; Mukunya et al., 2019; Scelza \& Hinde, 2019).

Finally, the application of the Sunrise Model helped us to verify the weight that culture has in maternal health care, and the multiple factors that interfere with the way of caring (educational, religious, social, economic, cultural, or technological factors).

The study has limitations, such as the small sample of people interviewed, the specific place, as well as those limitations of the oral sources themselves (memory loss, selective forgetfulness, social convenience). In addition, the results are represented only with one model, without comparing them with others. Therefore, as future lines it is proposed to replicate the study in other areas, and compare them with other cultural models. 


\section{INTERNATIONAL IMPLICATIONS FOR PRACTICE}

The fact of knowing the experiences of older women who gave birth at home help us to understand the origin and weight of some beliefs and practices conveyed from generation to generation ("quarantine," "evil eye," or cravings, for instance), and which survive nowadays in some pregnant women. These beliefs and practices are similar in different cultures, and are divided into two main categories (physiological aspects and psychosocial aspects). This fact is interesting to be considered, in order to provide cultural care these days, and generate a positive impact on women, their babies and their family.

On the other hand, we have verified the role that these older women, family, and relatives had as significant transmitters of maternal health information. This issue, added to the fact that these women gave birth at home, can provide us some keys to plan maternal health interventions in current affairs, which older women become involved as companions or counselors in some cases.

Finally, the application of the Sunrise Model has helped us to verify the weight that culture has in maternal health care, and the multiple factors that interfere with the way of caring. The application of models to real situations such as this one facilitates the reflection on essential aspects of our discipline-as it is maternal careand the graphic and simplified representation of that reality. Consequently, all this helps us to develop and improve our practice: as nurses, not only should we focus on knowing the physical aspects, but also the social and cultural circumstances surrounding the pregnant woman. Something that today seems to be especially relevant, as the WHO establish (Wilkinson \& Marmot, 2003) and on which theoretical nurses, like Leininger, had already placed value decades ago.

\section{REFERENCES}

Abdul-Mumin, K. H. (2016). Village midwives and their changing roles in Brunei Darussalam: A qualitative study. Women \& Birth, 29, e73-e81. doi:10.1016/j.wombi.2016.04.002

Abdulrehman, M. S., Woith, W., Jenkins, S., Kossman, S., \& Hunter, G. L. (2016). Exploring cultural influences of self-management of diabetes in Coastal Kenya: An ethnography. Global Qualitative Nursing Research, 3, 1-13. doi:10.1177/2333393616641825

Andina-Díaz, E. (2015). Valoración sobre la participación de lo doméstico en torno al parto. Creencias y prácticas populares en Almanza y Cebanico (Sahagún, León) durante la primera

AQ2 mitad del siglo XX. Tesis doctoral, Universidad de Alicante.

Benza, S., \& Liamputtong, P. (2014). Pregnancy, childbirth and motherhood: A meta-synthesis of the lived experiences of immigrant women. Midwifery, 30, 575-584. doi:10.1016/j.mi dw.2014.03.005

Bradley, S., McCourt, C., Rayment, J., \& Parmar, D. (2016). Disrespectful intrapartum care during facility-based delivery in sub-Saharan Africa: A qualitative systematic review and thematic synthesis of women's perceptions and experiences. Social Science Medicine, 169, 157-170. doi:10.1016/j.socscimed.2016.09.039 
Coast, E., Jones, E., Lattof, S., \& Portela, A. (2016). Effectiveness of interventions to provide culturally appropriate maternity care in increasing uptake of skilled maternity care: A systematic review. Health Policy and Planning, 31, 1479-1491. doi:10.1093/heapol/czw065

Dimmitt-Champion, J. (2013). Stories from a Mexican American Partera: Life on the TexasMexico Border. Journal of Transcultural Nursing, 24(1), 94-102. doi:10.1177/1043659612 452003

Dörnemann, J., \& Kelly, A. H. (2013). It is me who eats, to nourish him: A mixed-method study of breastfeeding in post-earthquake Haiti. Maternal and Child Nutrition, 9, 74-89.

Downe, S., Finlayson, K., Oladapo, O., Bonet, M., \& Gülmezoglu, M. (2018). What matters to women during childbirth: A systematic qualitative review. PLOS ONE, 13(4), e0194906. doi:10.1371/journal.pone.0194906

Fernández, I. (2014). La Nueva Revolución del Nacimiento: El Camino Hacia un Nuevo Paradigma. Ed Obstare.

Fernandes, E. T. B. S., Nascimento, E. R., Ferreira, S. L., Coelho, E. A. C., Silva, L. R., \& Pereira, C. O. J. (2018). Cervical cancer prevention among quilombola women in the light of Leininger's theory. Revista Gaúcha de Enfermagem, 39, e2016-0004. doi:10.1590/1983-1 447.2018.2016-0004

Gyaltsen, K., Gyal, L., Gipson, J. D., Kyi, T., \& Pebley. A. (2014). Reducing high maternal mortality rates in western China: A novel approach. Reproductive Health Matters, 22(44), 164173. doi:10.1016/S0968-8080(14)44802-X

Hernández, J. M., \& Echevarría, P. (2015). El nacimiento hospitalario e intervencionista: Un rito de paso hacia la maternidad. AIBR, Revista de Antropología Iberoamericana, 10(3), 401-426. doi:10.11156/aibr.100306

Joseph, F. I., \& Earland, J. (2019). A qualitative exploration of the sociocultural determinants of exclusive breastfeeding practices among rural mothers, North West Nigeria. International Breastfeeding Journal, 14, 38. doi:10.1186/s13006-019-0231-Z

Kandasamy, S., Vanstone, M., Oremus, M., Hill, T., Wahi, G., Wilson, J., ‥Anand, S. S. (2017). Elder women's perceptions around optimal perinatal health: A constructivist groundedtheory study with an Indigenous community in southern Ontario. CMAJ Open, 5(2). doi: 1 0.9778/cmajo.20160077

Kyei-Nimakoh, M., Carolan-Olah, M., \& McCann, T. V. (2017). Access barriers to obstetric care at health facilities in sub-Saharan Africa-a systematic review. Systematic Reviews, 6, 110. doi:10.1186/s13643-017-0503-X

Laza, C. (2015). Factores relacionados con la preferencia de las mujeres de zonas rurales por la partera tradicional. Revista Cubana de Salud Pública, 41 (3), 487-496.

Lledó, J., Pavía, J. M., \& Morillas, F. G. (2017). Transformaciones en la distribución semanal de nacimientos. Un análisis temporal 1940-2010. Revista Española Investigaciones Sociológicas, 159, 151-162. doi:10.5477/cis/reis.159.151

McFarland, M. R. (2011). Madeleine M. Leininger: Teoría de la diversidad y de la universalidad de los cuidados culturales. In M. Raile Alligood \& A. Marriner Tomey (Eds.), Modelos y

AQ4 Teorías en enfermería (pp. 454-479). Elsevier España.

Mukunya, D., Haaland, M. E. S., Tumwine, J. K., Ndeezi, G., Namugga, O., Tumuhamye, J., ... Nankabirwa, V. (2018). "We shall count it as a part of kyogero": Acceptability and considerations for scale up of single dose chlorhexidine for umbilical cord care in Central Uganda. BMC Pregnancy and Childbirth, 18, 476. doi:10.1186/s12884-018-2116-3

Mukunya, D., Nankabirwa, V., Ndeezi, G., Tumuhamye, J., Tongun, J. B., Kizito, S., ‥ Tumwine, J. (2019). Key decision makers and actors in selected newborn care practices: A community-based survey in Northern Uganda. International Journal of Environmental Research and Public Health, 16, 1723. doi:10.3390/ijerph16101723 
Owens, C., Dandy, J., \& Hancock, P. (2016). Perceptions of pregnancy experiences when using a community-based antenatal service: A qualitative study of refugee and migrant women in. Perth, Western Australia. Women \& Birth, 29, 128-137. doi:10.1016/j.wombi.2015.09 .003

Pati, S., Chauhan, A. S., Panda, M., Swain, S., \& Hussain, M. (2014). Neonatal care practices in a tribal community of Odisha, India: A cultural perspective. Journal of Tropical Pediatrics, 60(3), 238-244. doi:10.1093/tropej/fmu005

Scelza, B. A., \& Hinde, K. (2019). A biocultural study of grandmothering during the perinatal period. Human Nature, 30(4), 371-397. doi:10.1007/s12110-019-09356-2

Sumankuuro, J., Crockett, J., \& Wang, S. (2018). Sociocultural barriers to maternity services delivery: A qualitative meta-synthesis of the literatura. Public Health, 157, 77e85. doi:10. 1016/j.puhe.2018.01.014

Tavares, J. M. A. B., Lisboa, M. T. L., Ferreira, M. A., Valadares, G. V., \& Costa e Silva, F. V. (2016). Peritoneal dialysis: Family care for chronic kidney disease patients in home-based treatment. Revista Brasileira de Enfermagem, 69(6), 1107-1113. doi:10.1590/0034-71672016-0262

Taylor, S. J., \& Bogdan, R. (1990). Introducción a los métodos cualitativos de investigación. Paidós.

Tuncalp, O., Were, W. M., MacLennan, C., Oladapo, O. T., Gülmezoglu, A. M., Bahl, R., ... Bustreo, F. (2015). Quality of care for pregnant women and newborns-the WHO vision. British Journal of Obstetrics and Gynaecology, 122, 1045-1049. doi:10.1111/1471-0528.13 451

Van Dijik, M., Ruiz, M. J., Letona, D., \& García, S. G. (2013). Ensuring intercultural maternal health care for Mayan women in Guatemala: A qualitative assessment. Culture, Health \& Sexuality, 15(3), S365-S382. doi:10.1080/13691058.2013.779026

Wehbe-Alamah, H. (2015). Madeleine Leininger's theory of culture care diversity and universality. In M. C. Smith \& M. E. Parker (Eds.), Nursing theories and nursing practice (pp. 37-54). F.A. Davis Company.

Wilkinson, R. G., \& Marmot, M (Eds.). (2003). Social determinants of health: The solid facts. World Health Organization.

Withers, M., Kharazmi, N., \& Lim, E. (2018). Traditional beliefs and practices in pregnancy, childbirth and postpartum: A review of the evidence from Asian countries. Midwifery, 56, 158-170. doi:10.1016/j.midw.2017.10.019

World Health Organization. (n.d). Maternal mortality. https://www.who.int/news-room/fact -sheets/detail/maternal-mortality

World Health Organization. (2016). WHO recommendations: Intrapartum care for a positive childbirth experience: Transforming care of women and babies for improved health and wellbeing: executive summary. WHO. http://apps.who.int/iris/handle/10665/272447

AQ6 Disclosure. The authors have no relevant financial interest or affiliations with any commercial interests related to the subjects discussed within this article.

AQ7 Funding. The author(s) received no specific grant or financial support for the research, authorship, and/or publication of this article.

Correspondence regarding this article should be directed to Elena AndinaDíaz, Faculty of Health Science, Nursing and Physiotherapy Department, University of León, Vegazana Campus, S/N, 24071, León, Spain. E-mail: elena.andina@unileon.es 


\section{Author Queries:}

AQ1: AU: As per stylesheet, there should be 4 to 6 keywords. Please check and update.

AQ1: AU: Please provide missing closing double quote.

AQ2: AU: Andina-Díaz (2015) is not cited in the text. Please provide text citation or remove from the list.

AQ3: AU: Please provide page number for Kandasamy et al. (2017).

AQ4: AU: McFarland (2011) is not cited in the text. Please provide text citation or remove from the list.

AQ5: AU: Please confirm whether inserted page range \& volume number is appropriate in Scelza \& Hinde (2019).

AQ6: AU: Please confirm the accuracy of the Disclosure statement.

AQ7: AU: Please confirm the accuracy of the Funding statement. 